\title{
EDITORIAL
}

\section{Statins in patients with sepsis and ARDS: is it over? We are not sure}

\author{
Danny McAuley ${ }^{1,2}$, Pierre-Emmanuel Charles ${ }^{3}$ and Laurent Papazian ${ }^{4^{*}}$
}

๑) 2016 Springer-Verlag Berlin Heidelberg and ESICM

Statins are lipid-lowering agents which act by inhibiting 3-hydroxy-3-methylglutaryl coenzyme A reductase and are generally used for cardiovascular prevention. Statins, however, also present anti-inflammatory and immunomodulating effects which could be of interest in sepsis and acute respiratory distress syndrome (ARDS). Many experimental investigations and some epidemiological studies support this theoretical beneficial effect. However, recent interventional studies which showed no benefit have been discouraging and do not support the use of statins in septic and/or ARDS patients.

The mechanism of action in sepsis remains uncertain. Some data suggest that expression of Toll-like receptors could be downregulated, while others showed that mitochondria turn over could be promoted leading in turn to enhancement of antimicrobial host defence [1, 2]. However, it is still unclear to what extent inhibiting or at least mitigating the host inflammatory response could actually prevent sepsis mortality outside experimental conditions. Moreover, although a number of publications have raised the possibility that statins could exert protective effects in sepsis, their retrospective design makes it difficult to control for potentially "protective" confounders, especially the so-called healthy user effect [3]. Randomized clinical trials published so far failed to demonstrate a positive effect [4]. In addition, none of these studies reported evidence supporting an antiinflammatory effect of statins, suggesting that this could not be achieved with the recommended treatment regimen. Increasing doses could, however, be hazardous given the risk of adverse effects such as liver toxicity.

\footnotetext{
*Correspondence: laurent.papazian@ap-hm.fr

${ }^{4}$ URMITE UMR CNRS 7278, Hôpital Nord, Réanimation des Détresses

Respiratoires et Infections Sévères, Aix-Marseille Univ, APHM,

13015 Marseille, France

Full author information is available at the end of the article
}

For contrasting viewpoints, please go to doi:10.1007/s00134-016-4564-4 and doi:10.1007/s00134-016-4585-z.
However, patients with prior exposure to statins randomised to the treatment group had an improved outcome in one randomised controlled trial [5]. One could hypothesize that in those patients statins exert a "preventive" effect against the risk of an overwhelming inflammatory response from the host once subjected to an infectious insult. Accordingly, it has been shown that post-operative infectious complications were less likely in previous statin users [6]. Similarly, exposure to statins prior to the development of ventilator-associated pneumonia (VAP) was associated with a lower mortality rate, whereas they were ineffective when started once VAP was clinically overt [7, 8]. Altogether these findings suggest that statins should not be recommended as adjunctive therapy in septic patients, although a protective effect cannot be excluded if therapy is given prior to the infection onset. The risk of toxicity should, however, be considered even if simvastatin $60 \mathrm{mg}$ per day during 28 days was not associated with an increased rate of side effects as compared with the placebo group in a randomised controlled trial performed in mechanically ventilated patients presenting with a suspicion of VAP [8].

Despite recent improvements in the outcome of ARDS, pharmacological therapy for these patients remains limited. As for sepsis, data from recent large, multicentre, double-blind, randomised, placebo-controlled clinical trials in patients with ARDS have shown that, despite promising findings in preclinical and early phase clinical trials $[9,10]$, statins did not significantly improve clinical outcomes $[11,12]$. When secondary endpoints were analysed, rosuvastatin was associated with a small decrease in liver and renal failure-free days [13]. Although simvastatin was associated with an increase in adverse events in ARDS patients, there was no increase in serious adverse events [12]. An individual patient data meta-analysis is planned to quantify the safety and efficacy of statin therapy in ARDS (http://www.crd.york.ac.uk/PROSPERO/

\section{Springer}


display_record.asp?ID=CRD42014015389). Although the definition of ARDS identifies clinical phenotypes with predictive validity, as a result of the underlying biological differences within the overall clinical phenotype, pharmacological interventions may only be effective in a subpopulation of the overall cohort of patients with ARDS. In support of this hypothesis, Calfee et al. recently identified ARDS subphenotypes that respond differently to differing ventilator strategies [11]. It is also plausible to observe heterogeneity in treatment effect (HTE) by baseline risk [14]. Thus ARDS subsets with distinct pathophysiological mechanisms, such as a subgroup of patients with ARDS with evidence of endothelial dysfunction, may be more likely to benefit from statins. It is therefore of paramount importance to identify subgroups of ARDS and/or septic patients with a potential response to statins.

As for sepsis, the potential role of statins in the prevention of ARDS in patients at high risk of developing ARDS has not yet been evaluated. There is a body of evidence which supports statins as a pretreatment to improve outcomes in ARDS. The majority of data suggests that statins are effective when used as a pretreatment in animal models of sepsis and ARDS. As described above, in patients with sepsis, prior statin users randomised to continue treatment with atorvastatin, 28-day survival was improved. This supports the hypothesis that pretreatment with statins may be more effective [5]. A metaanalysis of 13 studies involving 254,950 patients found that treatment with statins in community-acquired pneumonia was associated with improved survival but that the effect was more pronounced if treatment was initiated in the community prior to hospital admission [15]. This is supported by data that pretreatment with simvastatin attenuated the systemic and pulmonary inflammatory response to lipopolysaccharide (LPS) in healthy human subjects [10]. Future studies could focus on randomising patients at high risk of ARDS, such as patients undergoing high-risk surgery such as oesophagectomy, to pretreatment with statins. There may be additional benefit in this setting with statins also potentially reducing cardiovascular and infectious complications.

Despite encouraging results obtained from experimental and epidemiological studies, the use of statins in a non-selected population of patients presenting with sepsis, ARDS or both is not able to improve the outcome. There are some differences regarding the anti-inflammatory properties among various statins which could explain discordant results. There is also a dose-dependent effect which should be considered when designing prospective studies. Finally, future studies should focus on the use of statins as a preventative or curative strategy in homogeneous populations selected by clinical phenotype (ARDS risk factor, type of infection) and/or by the use of biomarkers. However, at the present time, there is no indication for statins in patients with ARDS and/or sepsis.

\section{Author details}

${ }^{1}$ Centre for Experimental Medicine, Queen's University of Belfast, Belfast BT9 7AE, UK. ${ }^{2}$ Regional Intensive Care Unit, The Royal Hospitals, Grosvenor Road, Belfast BT12 6BA, UK. ${ }^{3}$ Service de Réanimation Médicale, Hôpital F. Mitterrand, CHU Dijon Laboratoire "Lipides Nutrition Cancer" UMR 866, INSERM, UFR Sciences de Santé, Université de Bourgogne, Dijon, France. ${ }^{4}$ URMITE UMR CNRS 7278, Hôpital Nord, Réanimation des Détresses Respiratoires et Infections Sévères, Aix-Marseille Univ, APHM, 13015 Marseille, France.

\section{Compliance with ethical standards}

\section{Conflict of interest}

DMcA reports personal fees from consultancy for GlaxoSmithKline (GSK), SOBI, Boehringer Ingelheim, Bayer and Peptinnovate. His institution, Queen's University Belfast, has received grants from the National Institute for Health Research (NIHR) and others, as well as funds from GSK for DMcA undertaking bronchoscopy as part of a clinical trial. In addition, DMcA also holds a patent for the use of a pharmacotherapy (not a statin) for treatment of ARDS awarded to Queen's University Belfast. PEC reports personal fees from consultancy for Astellas and Merck and grants from Pfizer. LP has no conflict of interest.

Received: 14 July 2016 Accepted: 15 July 2016

Published online: 17 October 2016

\section{References}

1. Moutzouri E, Tellis CC, Rousouli K, Liberopoulos EN, Milionis HJ, Elisaf MS, Tselepis AD (2012) Effect of simvastatin or its combination with ezetimibe on Toll-like receptor expression and lipopolysaccharide-induced cytokine production in monocytes of hypercholesterolemic patients. Atherosclerosis 225:381-387

2. Wang $Y$, Zhang MX, Meng $X$, Liu FQ, Yu GS, Zhang C, Sun T, Wang XP Li L, Wang YY, Ding SF, Yang JM, Zhang Y (2011) Atorvastatin suppresses LPS-induced rapid upregulation of Toll-like receptor 4 and its signaling pathway in endothelial cells. Am J Physiol Heart Circ Physiol 300:H1743-H1752

3. Ou SY, Chu H, Chao PW, Ou SM, Lee YJ, Kuo SC, Li SY, Shih CJ, Chen YT (2014) Effect of the use of low and high potency statins and sepsis outcomes. Intensive Care Med 40:1509-1517

4. Deshpande A, Pasupuleti V, Rothberg MB (2015) Statin therapy and mortality from sepsis: a meta-analysis of randomized trials. Am J Med 128(410-417):e411

5. Kruger P, Bailey M, Bellomo R, Cooper DJ, Harward M, Higgins A, Howe B, Jones D, Joyce C, Kostner K, McNeil J, Nichol A, Roberts MS, Syres G, Venkatesh B, ANZ-STATInS Investigators-ANZICS Clinical Trials Group (2013) A multicenter randomized trial of atorvastatin therapy in intensive care patients with severe sepsis. Am J Respir Crit Care Med 187:743-750

6. Schurr JW, Wu W, Smith-Hannah A, Smith CJ, Barrera R (2016) Incidence of sepsis and mortality with prior exposure of HMG-COA reductase inhibitors in a surgical intensive care population. Shock 45:10-15

7. Bruyere R, Vigneron C, Prin S, Pechinot A, Quenot JP, Aho S, Papazian $L$, Charles PE (2014) Impact of prior statin therapy on the outcome of patients with suspected ventilator-associated pneumonia: an observational study. Crit Care 18:R83

8. Papazian L, Roch A, Charles PE, Penot-Ragon C, Perrin G, Roulier P, Goutorbe P, Lefrant JY, Wiramus S, Jung B, Perbet S, Hernu R, Nau A, Baldesi O, Allardet-Servent J, Baumstarck K, Jouve E, Moussa M, Hraiech S, Guervilly C, Forel JM, STATIN-VAP Study Group (2013) Effect of statin therapy on mortality in patients with ventilator-associated pneumonia: a randomized clinical trial. JAMA 310:1692-1700 
9. Craig TR, Duffy MJ, Shyamsundar M, McDowell C, O'Kane CM, Elborn JS, McAuley DF (2011) A randomized clinical trial of hydroxymethylglutarylcoenzyme a reductase inhibition for acute lung injury (The HARP Study). Am J Respir Crit Care Med 183:620-626

10. Shyamsundar M, McKeown ST, O'Kane CM, Craig TR, Brown V, Thickett DR, Matthay MA, Taggart CC, Backman JT, Elborn JS, MCAuley DF (2009) Simvastatin decreases lipopolysaccharide-induced pulmonary inflammation in healthy volunteers. Am J Respir Crit Care Med 179:1107-1114

11. Calfee CS, Delucchi K, Parsons PE, Thompson BT, Ware LB, Matthay MA, NHLBI ARDS Network (2014) Subphenotypes in acute respiratory distress syndrome: latent class analysis of data from two randomised controlled trials. Lancet Respir Med 2:611-620

12. McAuley DF, Laffey JG, O'Kane CM, Perkins GD, Mullan B, Trinder TJ, Johnston P, Hopkins PA, Johnston AJ, McDowell C, McNally C, HARP-2
Investigators, Irish Critical Care Trials Group (2014) Simvastatin in the acute respiratory distress syndrome. N Engl J Med 371:1695-1703

13. National Heart, Lung, and Blood Institute ARDS Clinical Trials Network, Truwit JD, Bernard GR, Steingrub J, Matthay MA, Liu KD, Albertson TE, Brower RG, Shanholtz C, Rock P, Douglas IS, deBoisblanc BP, Hough CL, Hite RD, Thompson BT (2014) Rosuvastatin for sepsis-associated acute respiratory distress syndrome. N Engl J Med 370:2191-2200

14. Iwashyna TJ, Burke JF, Sussman JB, Prescott HC, Hayward RA, Angus DC (2015) Implications of heterogeneity of treatment effect for reporting and analysis of randomized trials in critical care. Am J Respir Crit Care Med 192:1045-1051

15. Chopra V, Rogers MA, Buist M, Govindan S, Lindenauer PK, Saint S, Flanders SA (2012) Is statin use associated with reduced mortality after pneumonia? A systematic review and meta-analysis. Am J Med 125:1111-1123 